\title{
Knockout of alanine racemase gene attenuates the pathogenicity of Aeromonas hydrophila
}

\author{
Dong Liu ${ }^{\dagger}$ (D) Ting Zhang ${ }^{\dagger}$, Yaping Wang, Murtala Muhammad, Wen Xue, Jiansong Ju and Baohua Zhao*
}

\begin{abstract}
Background: Aeromonas hydrophila is an opportunistic pathogen of poikilothermic and homoeothermic animals, including humans. In the present study, we described the role of Alanine racemase (alr-2) in the virulence of $A$. hydrophila using an alr-2 knockout mutant (A.H. $\Delta a / r$ ).

Results: In mouse and common carp models, the survival of animals challenged with A.H. Aalr was significantly increased compared with the wild-type (WT), and the mutant was also impaired in its ability to replicate in the organs and blood of infected mice and fish. The A.H. $\Delta$ alr significantly increased phagocytosis by macrophages of the mice and fish. These attenuation effects of alr-2 could be complemented by the addition of D-alanine to the $A$.

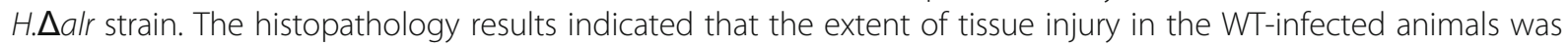
more severe than in the A.H. $\Delta a l r$-infected groups. The expression of 9 virulence genes was significantly downregulated, and 3 outer membrane genes were significantly up-regulated in A.H. $\Delta$ alr.
\end{abstract}

Conclusions: Our data suggest that alr-2 is essential for the virulence of $A$. hydrophila. Our findings suggested alanine racemase could be applied in the development of new antibiotics against $A$. hydrophila.

Keywords: Aeromonas hydrophila/ alanine racemase/ bacterial virulence

\section{Background}

Aeromonas hydrophila is a water-borne Gram-negative and facultative anaerobic bacterium that is widely distributed in nature. It is an opportunistic pathogen of poikilothermic and homoeothermic animals, including humans [1]. In fish, it causes motile aeromonas septicemia (MAS), a serious disease that leads to severe economic losses [2]. In humans, A. hydrophila can cause acute gastroenteritis, soft tissue infections, primary septicemia, meningitis, endocarditis, pneumonia, and empyema [3]. The pathogenicity of A. hydrophila is complex and it produces multiple virulence factors: adhesins, cytotoxins, hemolysins, lipases, nucleases, proteases, S-layers, lateral and polar flagella, type III and typeVI secretion systems, iron-binding systems, the capacity to form biofilms and mediate virulence factor expression through quorum sensing [4-6].
Alanine racemase (Alr; EC 5.1.1.1) is a pyridoxal-5'phosphate (PLP)-containing homodimeric enzyme that catalyzes the interconversion of $\mathrm{L}$-alanine to $\mathrm{D}$-alanine [7]. D-Alanine is an essential component of the peptidoglycan in the cell wall of both gram-positive and gram-negative bacteria [8]. Peptidoglycan (PG), the main component of the cell wall of bacteria, enables bacteria to endure adverse environments. Moreover, PG is also essential to maintaining cell shape and for proper growth and division [9]. The lack of alanine racemase in eukaryotes [10] makes this enzyme an attractive target for antimicrobial drug development $[11,12]$. Some studies have been conducted to identify the role of alanine racemase in the pathogenicity of Listeria monocytogenes, Mycobacterium tuberculosis, Mycobacterium smegmatis and Burkholderia pseudomallei K96243 [13-16].

\footnotetext{
* Correspondence: baohua519@126.com

${ }^{\dagger}$ Dong Liu and Ting Zhang contributed equally to this work.

College of Life Science, Hebei Normal University, Shijiazhuang 050024, China
}

(c) The Author(s). 2019 Open Access This article is distributed under the terms of the Creative Commons Attribution 4.0 International License (http://creativecommons.org/licenses/by/4.0/), which permits unrestricted use, distribution, and reproduction in any medium, provided you give appropriate credit to the original author(s) and the source, provide a link to the Creative Commons license, and indicate if changes were made. The Creative Commons Public Domain Dedication waiver (http://creativecommons.org/publicdomain/zero/1.0/) applies to the data made available in this article, unless otherwise stated. 
Recently, the molecular features of the putative alanine racemase Alr1and Alr3 (broad-spectrum amino acid racemase) from $A$. hydrophila were defined [17]. However, the biochemical features of these two racemases have not yet in-depth studied. Previously, we showed that the E. coli alr ${ }^{-}$dadx $x^{-}$double mutant MB2795 strain [18] complemented with alr-2 didn't require d-alanine for growth [19]. We showed the characterization of alanine racemase (Alr-2) in A. hydrophila and reported the knockout of the alr-2 gene resulting in cell wall damage and enhanced membrane permeability under D-alanine starvation. We also developed an efficient screening method for alanine racemase Alr-2 inhibitors and identified some effective inhibitors. These inhibitors are capable of inhibiting the growth of $A$. hydrophila. These results indicated that the alanine racemase Alr-2 is important for A. hydrophila [20, 21]. Although Alr has been well documented as closely associated with the viability and survival of various bacteria, its physiological importance in A. hydrophila has not been explored. In this work, we investigate the virulence properties of the alr-2 deletion mutant of $A$. hydrophila. We employed both murine and fish infection models to investigate the contribution of alr-2 for A. hydrophila infection. We also check the expression level of 12 virulence-related genes to the alr-2 knockout mutant. The aim of this study is to explore the contribution of alr-2 to the pathogenicity of $A$. hydrophila.

\section{Methods}

\section{Bacteria and culture conditions}

The strains used in this study are Aeromonas hydrophila HBNUAh01, which was isolated from sick Paralichthys olivaceus [22], and the alanine racemase gene

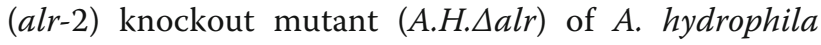
HBNUAh01. A.H. $\triangle$ alr mutant by deletion of alr-2 gene was constructed by homologous recombination using the suicide plasmid pK18mobsacB $[19,20]$. Strains were cultured in Luria-Bertani (LB, Oxoid; UK) medium at $30^{\circ} \mathrm{C}$. D-alanine was obtained from Sigma (St Louis, MO, USA). Counting of A. hydrophila was performed by serial dilution and spread plating on LB medium. The plates were incubated at $30^{\circ} \mathrm{C}$ for $48 \mathrm{~h}$ and colonies were counted and expressed as colony forming units (CFU)/ml. For each of the three independent experiments, two plates per dilution were used to calculate the results.

\section{Experimental animal}

Female 4- to 6-week-old BALB/c mice (Hebei CDC, Shijiazhuang, China) were kept 5 per cage in a cabinet at $23^{\circ} \mathrm{C}, 12 \mathrm{~h} / 12 \mathrm{~h}$ day/night cycle; water and food were provided ad libitum throughout the experiment. The common carp, Cyprinus carpio, L., (100-130 g) was obtained from the fish farm of Hebei Aquaculture Experimental Station (Shijiazhuang, China). The fish were maintained at $25-26^{\circ} \mathrm{C}$ in recirculating fresh water and acclimatized for 2 weeks before the experiments were performed. They were fed daily with commercial bream feed. All animal experimental procedures were strictly carried out according to the recommendations in the Guide for the Care and Use of the Laboratory Animals of Hebei Province in China. The animal experiment protocol was approved by the Animal Monitoring Committee of Hebei Normal University. All efforts were made to minimize suffering.

\section{Anesthesia and euthanasia}

Female BALB/c mice used for the experimental procedures in this work were sacrificed by cervical dislocation after light anesthesia by intraperitoneal injection of pentobarbital $(50 \mathrm{mg} / \mathrm{kg})$. The common carp, Cyprinus carpio, L. were euthanized in $30-40 \mathrm{mg} / \mathrm{ml}$ buffered ethyl 3-aminobenzoate methanesulfonate (MS-222).

\section{Virulence assays}

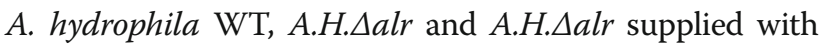
$0.5 \mathrm{mM}$ D-ala in LB medium $(\mathrm{C} \Delta a l r)$ were grown at $37^{\circ} \mathrm{C}$ in LB to log phase, harvested by centrifugation, washed twice, and normalized to the required inoculums in saline by adjusting the suspension to the appropriate $\mathrm{OD}_{600}$ value justified by the viable counts. Six groups of BALB/c mice (5 mice/ group) and 6 groups of common carp (6 carps/ group) received an intraperitoneal (i.p.) injection with $1.0 \mathrm{ml}$ of suspension containing $1.5 \times 10^{7}$ to $8 \times 10^{8}$ CFUs of bacteria in sterile Dulbecco's phosphate-buffered saline (DPBS). The mice and carp were observed for 14 days to determine the survival rate. $\mathrm{LD}_{50}$ values were calculated using SPSS 16.0 IBM modeler.

For virulence comparisons, 20 mice and 20 fish were randomly divided into 2 groups and were inoculated i.p. with $3 \times 10^{7} \mathrm{CFUs} /$ mouse and $3 \times 10^{8} \mathrm{CFUs} /$ carp of the WT or A.H.Aalr strain. Animals were monitored for up to two weeks to evaluate the survival rate [23].

\section{Macrophage-killing assays}

Murine peritoneal macrophages were prepared as described [16] by peritoneal lavage of the BALB/c mice. The peritoneal exudate cells were seeded in 96-well plates at a density of $3 \times 10^{5}$ cells per well. The macrophages were selected by adherence after $2 \mathrm{~h}$ of culture at $37^{\circ} \mathrm{C}$ in a $5 \% \mathrm{CO}_{2}$-humidified incubator; non-adherent cells were removed by washing with PBS and fresh RPMI 1640 medium (Sigma-Aldrich, USA) supplemented with $10 \%$ fetal bovine serum (FBS), $15 \mathrm{mM}$ 
Hepes, $2 \mathrm{mM}$ L-glutamine, $1 \mathrm{mM}$ sodium pyruvate (Sigma-Aldrich), and penicillin/ streptomycin at $100 \mathrm{U} / \mathrm{ml}$

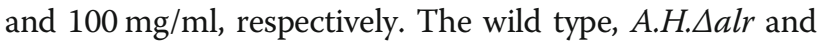
$\mathrm{C} \Delta$ alr strains were sub-cultured to $\mathrm{OD}_{600}=0.5$, collected and opsonized in RPMI 1640 medium. They were then added at a multiplicity of infection of 10 to the macrophage monolayers and incubated for $1 \mathrm{~h}$ to permit phagocytosis of the opsonized bacteria by the macrophages. As A. hydrophila were sensitive to gentamicin (Sigma-Aldrich, USA) [24], extracellular bacteria were washed two times with pre-warmed RPMI medium containing $10 \mu \mathrm{g} / \mathrm{ml}$ of gentamicin for $1 \mathrm{~h}$. The infected macrophages were lysed with $1 \%$ Triton X-100 in PBS to allow for enumeration of the surviving bacteria on the LB agar plates.

Head-kidney (HK) macrophages from common carp were prepared as described previously [25]. The cells were distributed into 96 -well tissue culture plates $\left(1 \times 10^{6}\right.$ cells/well $)$ and cultured at $22^{\circ} \mathrm{C}$ in Leibovitz medium (L-15) (Thermo Scientific HyClone, China) supplemented with 10\% FBS and $1 \%$ penicillin and streptomycin. Macrophages were in-

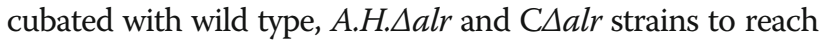
a multiplicity of infection of 10 . The plates were incubated at $28^{\circ} \mathrm{C}$ for $1 \mathrm{~h}$. The percent survival was determined by performing serial dilutions and plating on LB media plates and calculated as (CFUs with macrophages/CFUs without macrophages) $\times 100 \%$.

\section{Whole blood killing assays}

A blood killing assay was performed as described [26] with some changes. A. hydrophila WT, A.H.Aalr and CAalr were grown, washed, and resuspended in PBS. Diluted cultures of log-phase bacteria $(100 \mu \mathrm{l})$ containing $10^{3} \mathrm{CFU}$ were combined with $450 \mu \mathrm{l}$ heparinized mouse blood, and the mixtures were incubated at $37^{\circ} \mathrm{C}$ with rotation for $1 \mathrm{~h}$. The percentage of live bacteria was subsequently determined by plating and calculated as follows: (CFUs after co incubation/ CFUs in original inoculums $) \times 100 \%$. The negative control was made by direct inoculation of the $100 \mu \mathrm{l}$ of PBS directly into heparinized mouse blood. Experiments were performed using blood from at least three individual mice.

\section{Competitive growth assays}

The competitive assay was performed as described [27]. Overnight cultures of the WT and A.H.Aalr mutant were sub-cultured to $\mathrm{OD}_{600}=0.5$. The amount of bacteria was determined by performing serial dilutions and plating on LB media plates at $37^{\circ} \mathrm{C}$ for $24 \mathrm{~h}$. Both WT and A.H. $\Delta a l r\left(10^{7} \mathrm{CFU}\right)$ were mixed together in a ratio of $1: 1$ and injected i.p. $(0.5 \mathrm{ml} / \mathrm{mice})$ into $6 \mathrm{BALB} / \mathrm{c}$ mice. Mice were euthanized at $24 \mathrm{~h}$ after inoculation, and the abdominal cavity was lavaged with $1 \mathrm{ml}$ PBS. The samples were then diluted and plated onto LB agar plates. Six common carp were i.p. injected with the mixture $(0.5 \mathrm{ml} / \mathrm{fish})$. Fish were euthanized at $24 \mathrm{~h}$ after inoculation, and the ascites samples were diluted and plated onto LB agar

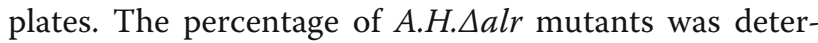
mined by analyzing 50 colonies of each sample by PCR using the following primers designed for validat-

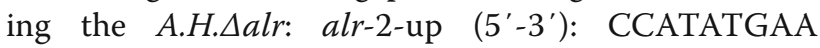
CACAGTTACGGCCA; alr-2-down (5'-3'): GTTC GAACGGCCAGCTTCAACA [20]. The competitive index was determined as the $\Delta a l r$ : WT ratio in the samples.

\section{Determination of viable bacteria invasion in susceptible tissues}

To assess the dissemination abilities of the A. hydrophila strains in mice and common carp, female $\mathrm{BALB} / \mathrm{c}$ mice (5 mice/ group) and common carp (5 carps/ group) were challenged i.p. with the sub-cultured WT, A.H. $\Delta a l r$ and C. $\Delta a l r$ at a dose of $0.3 \times 10^{7}$ CFUs / mouse and $1.5 \times 10^{8}$ CFUs / carp. At $24 \mathrm{~h}$ following injection, the mice and common carp were euthanized, the liver, kidney, spleen, blood and ascites were collected, and the organ weights were determined. Bacterial load in the organs and samples was determined by serial dilution and plating on LB agar plates for $24 \mathrm{~h}$ [28].

\section{Histopathology}

$\mathrm{BALB} / \mathrm{c}$ mice were challenged i.p. with the sub-cultured WT and A.H.Aalr at dose of $1.7 \times 10^{7}$ CFUs / mouse and $1.2 \times 10^{7}$ CFUs / mouse respectively. The common carp were challenged i.p. with the

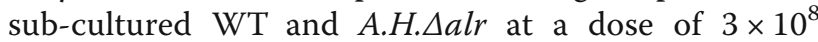
CFUs / carp. The collected liver, kidney and spleen samples from the mice and common carp were obtained after $24 \mathrm{~h}$ of infection, fixed in $10 \%$ buffered formalin (PBS; $\mathrm{pH} 7.2$ ) for $24 \mathrm{~h}$, and embedded in paraffin. The animals injected with physiological saline served as negative controls. Sections $(3 \mu \mathrm{m})$ were stained with Hematoxylin and Eosin (H\&E) according to published methods [29] and scanned using an Aperio ScanScope (Aperio Technologies, Vista, CA, USA).

\section{Quantitative real-time PCR}

To test the effect of the deletion of $a l r-2$ on other significant virulence genes, quantitative real-time reverse transcription-PCR was performed to quantify the expression level of the 13 virulence genes. The virulence genes used included flagellar and pilin family protein genes (flgE, flgL and pilB), a major adhesion subunit gene $(c b l A)$, type VI secretion system-related genes (vasH and $\operatorname{traA}$ ), a type Ш 
secretion system gene (asc V), a serine peptidase gene $(\operatorname{deg} Q)$, an aerolysin gene $(\operatorname{aer} A)$, a hemolysin gene (hlyA), two outer membrane protein genes (ompA and ompTS) and a lipopolysaccharide (LPS) heptosyltransferase II gene $(r f a F)$. The primers and method were as described [30]. Total RNA was isolated using the RNAprep pure Cell / Bacteria Kit (Tiangen, China). Total RNA concentration was determined from the absorbance at $260 \mathrm{~nm}$. The first-strand cDNA was synthesized using the FastQuant RT Kit (With gDNase) kit (Tiangen, China). Controls without reverse transcription (RT) verified lack of DNA contamination. The analysis was performed on a Real-Time PCR system ABI 7500 (ABI, USA) using SYBR green I fluorescent dye. The reactions were performed in a $10 \mu \mathrm{L}$ volume, and the cycling parameters were $95^{\circ} \mathrm{C}$ for $20 \mathrm{~s}, 55^{\circ} \mathrm{C}$ for $20 \mathrm{~s}$, and $72{ }^{\circ} \mathrm{C}$ for $20 \mathrm{~s}$ at 45 cycles. Threshold cycles and dissociation curves were determined, and the gene expression levels were normalized to those of the $16 \mathrm{~S}$ rRNA (which showed an invariant expression under the experimental conditions) [31]. ABI 7500 software v2.0.6 was used to calculate the relative expression of the mRNA target genes.

\section{Statistical analysis}

Statistical analysis was performed with SPSS 16.0 (SPSS Inc. USA) and the Prism software program 6.0 (GraphPad Soft-ware, Inc. USA). Survival data were analyzed with the log-rank test. Except for the survival study, the $P$ values in other experiments were obtained using Student's $t$-test. $P$ values $<0.05$ and $<0.01$ were considered statistically significant and highly statistically significant, respectively.

\section{Results}

alr-2 contributes to $A$. hydrophila pathogenesis in both mice and fish infection

A. hydrophila and its mutants were tested in mouse and common carp models for virulence by lethal dose 50 $\left(\mathrm{LD}_{50}\right)$ determinations (Table 1 and Table 2). In mice,

Table 1 Calculations of the $\mathrm{LD}_{50}$ values of the WT and A.H.Dalr strains tested in mice

\begin{tabular}{|c|c|c|c|c|}
\hline \multirow{2}{*}{$\begin{array}{l}\text { Dose of } \\
\text { challenge (CFUs) }\end{array}$} & \multicolumn{2}{|c|}{ Number of deaths } & \multicolumn{2}{|c|}{ Survival rate (\%) } \\
\hline & $\overline{W T}$ & A.H. $\Delta$ alr & $\overline{W T}$ & A.H. $\Delta$ alr \\
\hline $2.4 \times 10^{8}$ & 5 & 5 & 0 & 0 \\
\hline $0.9 \times 10^{8}$ & 5 & 3 & 0 & 40 \\
\hline $4.5 \times 10^{7}$ & 5 & 2 & 0 & 60 \\
\hline $3 \times 10^{7}$ & 4 & 0 & 20 & 100 \\
\hline $1.5 \times 10^{7}$ & 2 & 0 & 60 & 100 \\
\hline $\operatorname{LD}_{50}\left(10^{7}\right)$ & 1.7 & 7 & & \\
\hline
\end{tabular}

Table 2 Calculations of the $\mathrm{LD}_{50}$ values of the WT and A.H. $\Delta$ alr strains tested in common carp

\begin{tabular}{|c|c|c|c|c|}
\hline \multirow{2}{*}{$\begin{array}{l}\text { Dose of } \\
\text { challenge (CFUs) }\end{array}$} & \multicolumn{2}{|c|}{ Number of deaths } & \multicolumn{2}{|c|}{ Survival rate (\%) } \\
\hline & WT & A.H.Dalr & WT & A.H. $\Delta$ alr \\
\hline $8 \times 10^{8}$ & 6 & 5 & 0 & 17 \\
\hline $5 \times 10^{8}$ & 6 & 3 & 0 & 50 \\
\hline $3 \times 10^{8}$ & 5 & 1 & 16 & 83 \\
\hline $1.5 \times 10^{8}$ & 3 & 0 & 50 & 100 \\
\hline $1 \times 10^{8}$ & 2 & 0 & 67 & 100 \\
\hline $\operatorname{LD}_{50}\left(10^{8}\right)$ & 1.4 & 5.1 & & \\
\hline
\end{tabular}

the LD50 value of the A.H.Aalr strain $\left(7 \times 10^{7}\right.$ CFUs) was approximately 4.1-fold higher than the WT $\left(1.7 \times 10^{7}\right.$ CFUs). In the common carp, the $\mathrm{LD}_{50}$ value of the WT strain tested was $1.4 \times 10^{8}$ CFUs, while that of the A.H.Dalr was $5.1 \times 10^{8}$ CFUs, which was 3.6-fold compared to the WT. The experiment was conducted at three separate times, and the results were the average of three experiments.

The virulence of the WT and A.H.Aalr strains was assessed with $3 \times 10^{7}$ CFUs / mouse and $3 \times 10^{8}$ CFUs / carp of the WT or A.H.Aalr strain. Most dying mice in the WT group show severe clinical signs, such as prostration depression, weakness, and anorexia. Eight out of the 10 mice died at 4 days post-infection

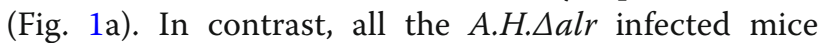
survived without exhibiting any clinical signs. The mortality rate of the common carp infected with the WT strain was $100 \%$, and death occurred at 2 days post-infection (Fig. 1b). Most dying fish showed clinical signs typical hemorrhagic septicemia, such as ulcerative lesions and skin hemorrhages. The mortality rate was $17 \%$ for the A.H. $\Delta a l r$ infected fish, and the surviving fish show no evident external lesions (Fig. 1b). These data indicate an important role of Alr-2 in A. hydrophila virulence.

alr-2 contributes to bacterial survival in macrophages and in mouse blood

To determine if alr-2 promote A. hydrophila survival against the innate immune response, we com-

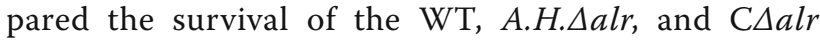
strains in mice and fish head-kidney macrophages.

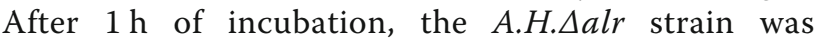
killed more efficiently than the WT strains $(P<0.01)$ (Fig. 2a and b). Next, we examined whether Alr-2 protected the WT strain in whole mouse blood. In whole

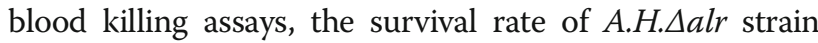
(87.7\% reduction) was significantly reduced compared to WT $(59.2 \%$ reduction $)(P<0.01)$ (Fig. $2 \mathrm{c})$. The survival 

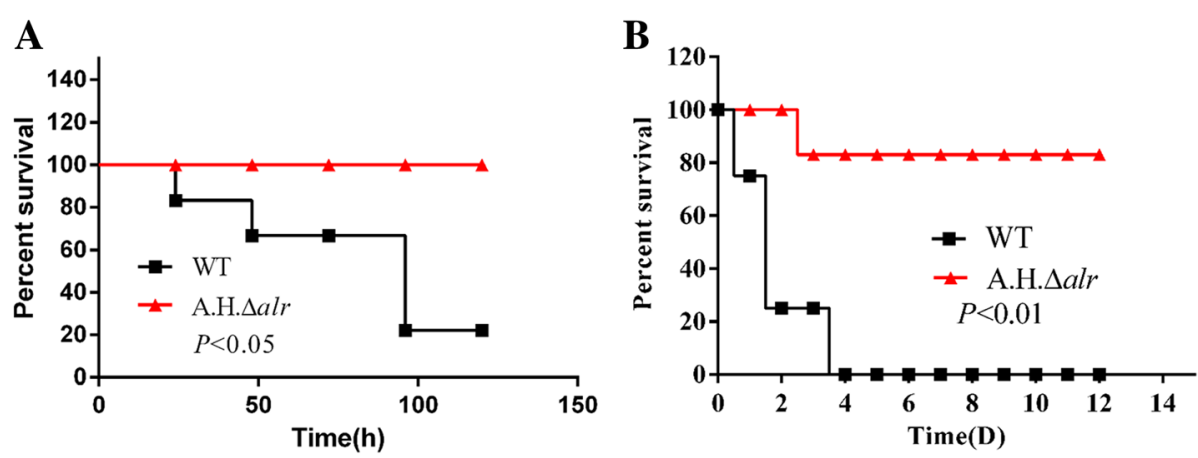

Fig. 1 Alr-2 contributes to the virulence of A. hydrophila. a Survival curves for mice infected with WT type and A.H. $\Delta$ alr strains by the i.p. route. b Survival curves for fish challenged with WT and A.H. Aalr strains

rate of complementary CAalr strain is similar to that of WT $(P>0.05)$.

\section{alr-2 contributes to $A$. hydrophila survival in vivo}

In the study, ascites or hemorrhaging in the abdominal cavity were observed in mice and fish infected with $A$. hydrophila. In comparison with bacterial load in the ascites of WT-infected group, After $24 \mathrm{~h}$ post-inoculation, the bacterial of A.H. $\Delta a l r$ infected group was significantly lower $(P<0.01)$, while the CAalr strain behaved similarly to the WT strain in the assay $(P>0.05)$ (Fig. 3a, b). The results suggest that A.H. $\Delta$ alr could not survive effectively in vivo. We also conducted competitive growth assays in both the mouse and fish abdominal cavity model. Both the competitive indices are approximately $0.55-$ 0.6 , which is significantly less than $1 \quad\left({ }^{*} P<0.05\right.$, Fig. 3c), indicating an advantage for the WT. These experiments showed that the A.H. $\Delta a l r$ strain impaired $A$. hydrophila to survival in vivo.

\section{alr-2 enhances $A$. hydrophila dissemination in multiple organs}

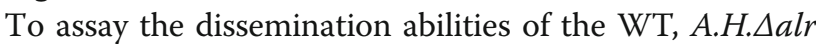
and $\mathrm{C} \Delta a l r$ strains, three strains were inoculated i.p. into BALB/c mice and common carp, respectively. After $24 \mathrm{~h}$ post-infection of mice, the bacterial counts in the tissues

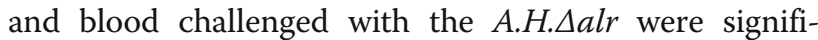
cantly lower $(P<0.01)$ than those of the WT. The concentrations of bacteria in the mice tissues and blood infected with $\mathrm{C} \Delta a$ alr were not significantly different or higher than those of the WT $(P>0.05)$ (Fig. 4a). The changes of bacterial concentrations in the fish tissues and blood are similar to those of the mice (Fig. 4b). These results indicated that alr-2 promoted bacterial systemic dissemination to different organs.

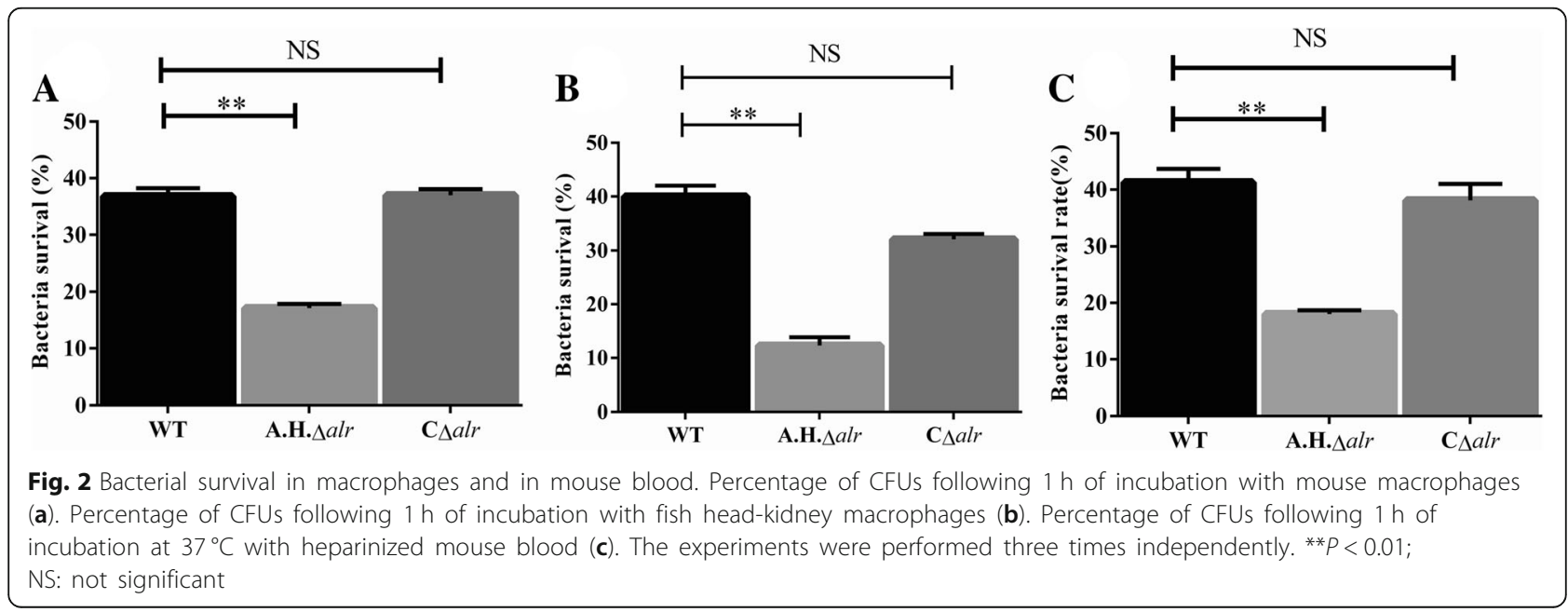



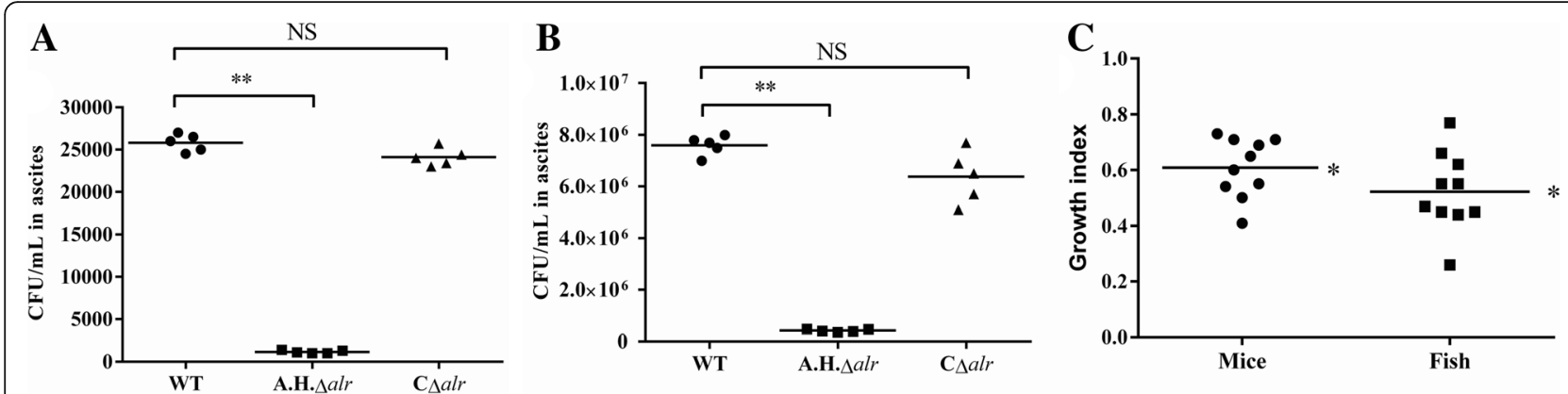

Fig. 3 Role of Alr-2 in resistance against clearance in vivo. a Bacterial loads recovered from mice ascites after $24 \mathrm{~h}$ post-i.p. inoculation. $\mathbf{b}$ Bacterial

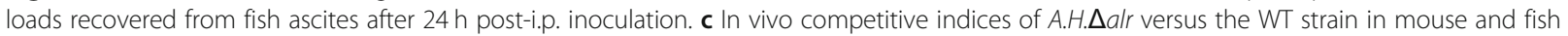
ascites. ${ }^{*} P<0.01 ;{ }^{*} P<0.05 ;$ NS: not significant

\section{Histopathology}

Histopathological studies were carried out to examine the pathological changes in the liver, spleen and kidney of the infected mice and fish. The organ architecture of animals infected by A.H.Salr (Fig. 5 panels E, F, G and H) was normal. In the group of mice and fish infected with the WT bacteria (Fig. 5, panels a, b, c and d), several pathological tissue changes were observed. The livers of the mice showed extensive and mild cell edema and deterioration, cytoplasm was loose (black arrows in Fig. 5, panel a) and occasional calcification. The spleens of the mice showed a large number of lymphocytes necrosis in the splenic nodules (black arrows in Fig. 5, panel b), irregular structures of splenic nodules and neutral expansion were observed, lymphocytosis and adjacent splenic nodules were connected. The kidneys of the mice showed renal tubular epithelial cell extensive edema and degeneration, cytoplasm loose or vacuolar (black arrows in Fig. 5, panel c), renal tubular epithelial cell necrosis, nuclear condensation (arrows in Fig. 5, panel c), cell necrosis and calcification (yellow arrows in Fig. 5, panel c). The livers of the common carp showed that the cytoplasm of the hepatocytes is vacuolated. Visible hemosiderin deposition was seen in the hepatic sinusoid and intravasculature (black and red arrows in Fig. 5, panel d).

\section{Expression of various virulence genes}

Quantitative real-time PCR (RT-qPCR) showed that the expression levels of 9 genes, flgL, pilB, cblA, vasH, $\operatorname{tra} A, \operatorname{deg} Q, \operatorname{aer} A, h l y A$ and $a s c V$, were significantly

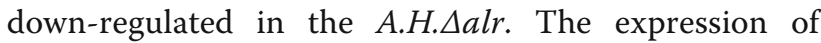
ompA, ompTS and $r f a F$ was significantly up-regulated in the A.H.Aalr. The expression of flgE shows no obvious change (Fig. 6).

\section{Discussion}

To confirm the effect of alr-2 on virulence, in vivo infection experiments with the mouse and common carp models were performed. Compared with the WT-infected group, the LD50 of the A.H.Aalr mutant was significantly increased. Survival of animals challenged with the A.H.Aalr was significantly increased, and the mutant also showed impaired replication in the tissues and blood. These results indicated that the alr-2 gene plays an important role in $A$. hydrophila virulence. These attenuation effects of alr-2 could be complemented by the addition of D-alanine to the A.H.Aalr strain.

In this study, we demonstrated that the Alr-2 deficient mutant A.H.Aalr lost viability in the murine peritoneal macrophages and HK macrophages growing in cell culture medium without added $\mathrm{D}$-alanine compared to the WT strain. Addition of $0.5 \mathrm{mM}$ D-alanine to the medium allowed A.H.Aalr to survive intracellularly. Some studies that have demonstrated that alanine racemase deficient mutants of $B$. pseudomallei K96243, L. monocytogenes and M. tuberculosis lost viability in murine macrophages and required exogenous D-alanine to achieve intracellular survival.

The results demonstrated that the virulence of A.H.Dalr was attenuated in both mice and fish, with reductions in the dissemination capacities and mor-

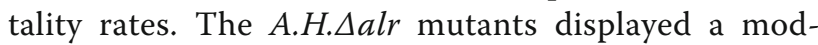
est decrease in virulence which was lower than other knockout models of virulence determinants in Aeromonas hydrophila, summarized by Rasmussen-Ivey et al. [32]. Many proteins have proven to be important factors for the pathogenicity of A. hydrophila. In one study, a nuclease $(a h n)$ deletion mutant was shown to attenuate the virulence of $A$. hydrophila in both fish and mice [27]. Jiang et al. reported that the histone deacetylase is an important regulatory protein 


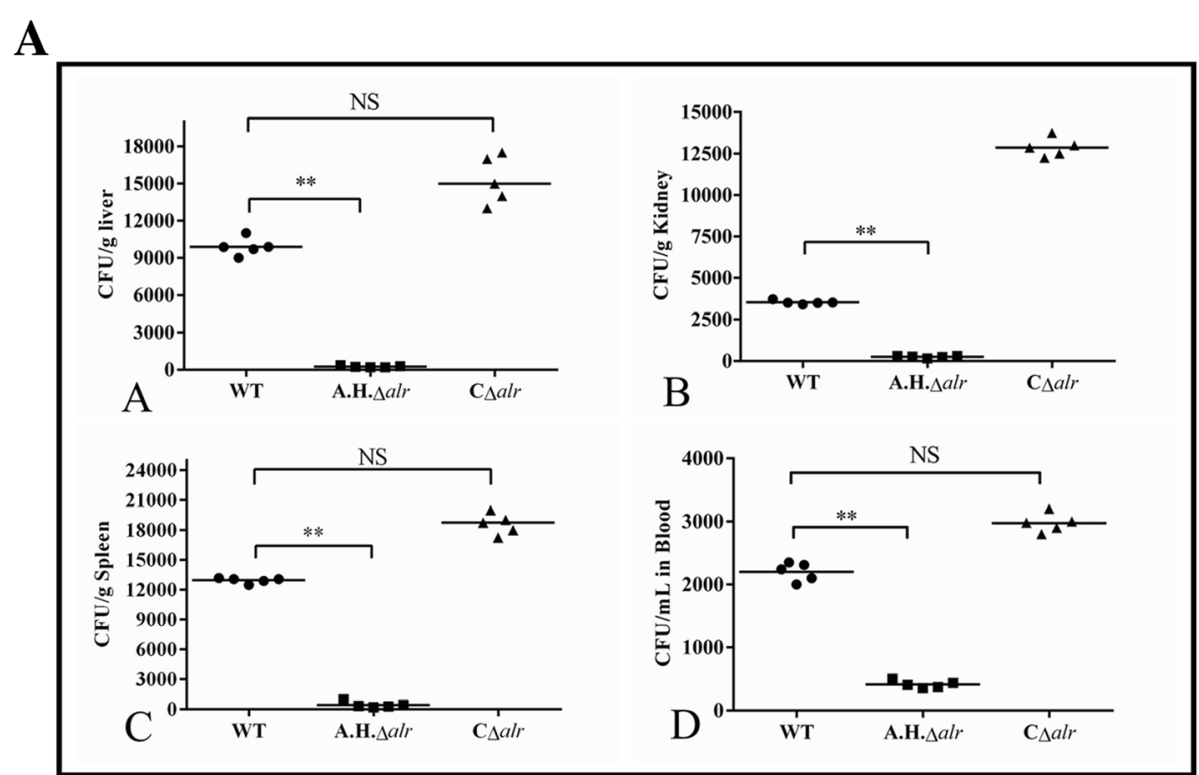

B

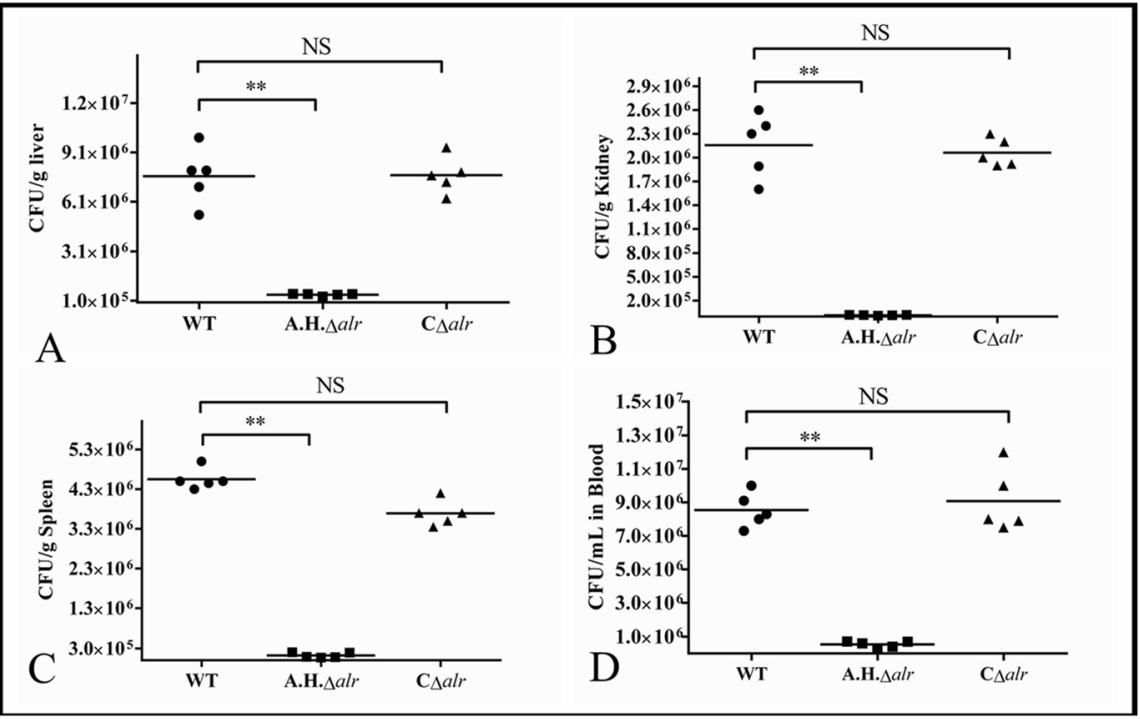

Fig. 4 Colonization of various tissues of mice (a) and the common carp (b) by the WT, A.H. $\Delta$ alr and C $\Delta$ alr strains. Bacterial counts in the spleen, liver, kidney and blood were examined at $24 \mathrm{~h}$ post infection. The data shown are the means for the results from three independent experiments, and the bacterial cell data shown are the limits of detection. Statistical analyses were performed by a repeated measures test with a Turkey test

contributing to the pathogenicity of $A$. hydrophila [30].

Quantitative real-time PCR showed that deletion of alr-2 resulted in no expression changes in flgE. The expression levels of the outer membrane protein (OMPS) genes (ompA, ompTS) and $r f a F$ were up-regulated. In gram-negative bacteria, the $r f a F$ gene is responsible for LPS biosynthesis [33]. The OMPS and LPS of the bacteria participate in maintaining bacterial cell integrity, adapting to the environment and protecting the cell from toxic compounds [34, 35]. As the knockout of the alr-2 of $A$. hydrophila leads to cell wall damage and enhanced membrane permeability [20], we predicted that the bacterium will produce more OMPS and LPS to stabilize the outer membrane and protect itself from toxic compounds.

The down-regulation of 9 genes, including $f l g L$, pilB, vasH, traA, $\operatorname{deg} Q, \operatorname{cblA}$, ascV, hlyA and aerA, is closely related to the motility, adhesion and virulence of $A$. hydrophila. FlgL and pilB are all 

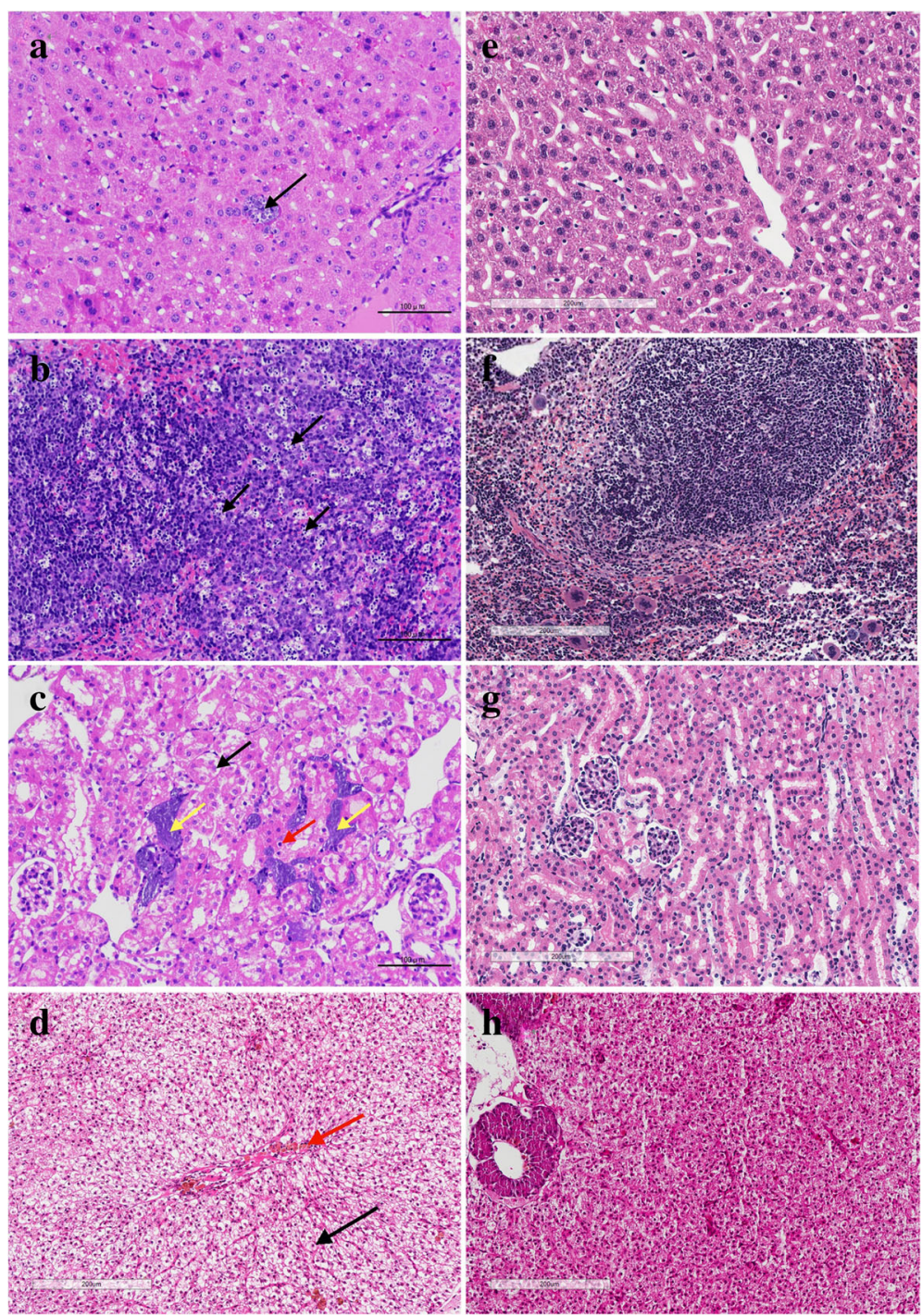

Fig. 5 Histological examination of sampled tissues (HE-stained; Scalebar = $200 \mu \mathrm{m}$ ). a Liver of the mouse infected with the WT strains. b Spleen of the mouse infected with the WT strains. c Kidney of the mouse infected with the WT strains. $\mathbf{d}$ Liver of the common carp infected with the WT

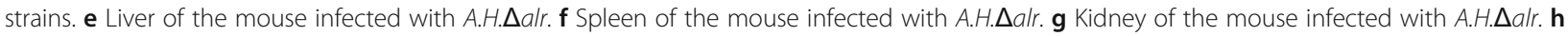
Liver of the common carp infected with A.H. $\Delta$ alr

reported to be correlated with the adhesion of $A$. hydrophila [36].

The genes of $v a s H, \operatorname{traA}, \operatorname{asc} V, \operatorname{deg} Q, \operatorname{aer} A$, and $h l y A$ are all correlated with the virulence of $A$. hydrophila. The vasH and asc $V$ mutants in A. hydrophila showed less toxicity and virulence in comparison with the wild-type strain [37, 38]. The serine peptidase encoded by $\operatorname{deg} Q$ is used for the removal and correction of harmful proteins. This protein is an essential protein required for $E$. coli growth at high temperatures [39]. The toxins encoded by aerA and $h l y A$, were all major virulence factors of $A$. hydrophila [40]. In this study, the virulence of $A$. hydrophila to mice and fish was significantly attenuated after deletion of alr-2. These results are consistent with the gene expression results.

\section{Conclusions}

We reveal that the alr-2 gene contributes to the virulence of $A$. hydrophila in mice and common carp. We identified that the deletion of alr-2 attenuates survival in macrophages of mice and fish. The alr-2 gene can influence the expression of 12 crucial virulence genes. Our data suggest that the alr-2 gene is 


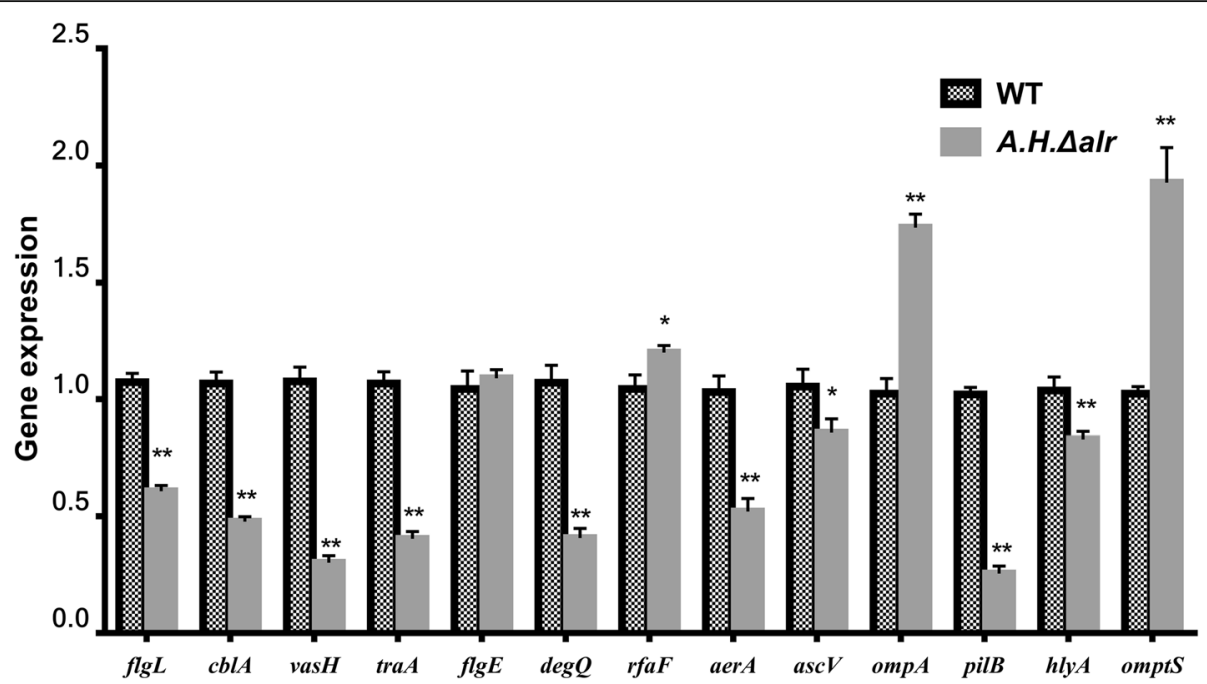

Fig. 6 Expression studies by quantitative real-time PCR: relative transcript profiles 13 virulence-related genes of A. hydrophila. 16S rRNA was used as the internal control for normalization the relative expression folds of individual transcripts. Results are mean of at least three independent experiments and the standard deviation (SD) is indicated by the error bars. Significance analysis was done by Student's t-test, ${ }^{*} P<0.05$, **P $P 0.01$

essential for the survival and pathogenicity of $A$. hydrophila, which provides a novel target for drug design.

\section{Abbreviations}

A. hydrophila: Aeromonas hydrophila; CFU: Colony forming units; DPBS: Dulbecco's phosphate-buffered saline; FBS: Fetal bovine serum; H\&E: Hematoxylin and Eosin; HK: Head-kidney; i.p: intraperitoneal; LD ${ }_{50}$ : Lethal dose 50; MAS: Motile aeromonas septicemia; OMPS: Outer membrane protein; PG: Peptidoglycan; PLP: Pyridoxal-5'-phosphate; RTqPCR: Quantitative real-time PCR

\section{Acknowledgements}

Not applicable.

\section{Funding}

This work was supported by the Natural Science Foundation of Hebei Province (C2013205103), the Out-standing youth Foundation of Department of Education of Hebei Province (YO2014026), the Research Fund of Hebei Normal University (L2016Z03), the State Key Laboratory of Pathogen and Biosecurity (Academy of Military Medical Science) (SKLPBS1529) and the Science and technology research project of Hebei University (ZD2018070).

\section{Availability of data and materials}

The data generated or analyzed during this study are included in this published article. Additional data available from the corresponding author on reasonable request.

\section{Authors' contributions}

WYP, ZBH and LD projected the study, assessed, and interpreted the results. $Z T$, WYP, and MM executed the experiments; LD prepared the manuscript, XW completed the Macrophage-Killing and Histopathology experiments. JJS assisted in the Quantitative real-time PCR. All authors read and approved the final manuscript.

\section{Ethics approval and consent to participate}

All animal experimental procedures were strictly carried out according to the recommendations in the Guide for the Care and Use of the Laboratory Animals of Hebei Province in China. The animal experiment protocol was approved by the Animal Monitoring Committee of Hebei Normal University. All efforts were made to minimize suffering.
Consent for publication

Not applicable.

\section{Competing interests}

The authors declare that they have no competing interests.

\section{Publisher's Note}

Springer Nature remains neutral with regard to jurisdictional claims in published maps and institutional affiliations.

Received: 30 January 2018 Accepted: 17 March 2019

Published online: 02 April 2019

\section{References}

1. Singh V, Chaudhary DK, Mani I, Jain R, Mishra BN. Development of diagnostic and vaccine markers through cloning, expression, and regulation of putative virulence-protein-encoding genes of Aeromonas hydrophila. J Microbiol. 2013;51:275-82.

2. Saraceni PR, Romero A, Figueras A, Novoa B. Establishment of infection models in zebrafish larvae (Danio rerio) to study the pathogenesis of Aeromonas hydrophila. Front Microbiol. 2016;7:1219.

3. Janda JM, Abbott SL. The genus Aeromonas: taxonomy, pathogeniticy and infection. Clin Microbiol Rev. 2010;23:35-73.

4. Tomás JM. The main Aeromonas pathogenic factors. ISRN Microbiol. 2012; 2012:256261.

5. Zhao YH, Shaw JG. Cross-talk between the Aeromonas hydrophila type III secretion system and lateral flagella system. Front Microbiol. 2016;7:1434.

6. Alperi A, Figueras MJ. Human isolates of Aeromonas possess Shiga toxin genes (st $\times 1$ and stx2) highly similar to the most virulent gene variants of Escherichia coli. Clin Microbiol Infect. 2010;16:1563-7.

7. di Salvo ML, Florio R, Paiardini A, Vivoli M, D'Aguanno S, Contestabile R. Alanine racemase from Tolypocladium inflatum: a key PLP-dependent enzyme in cyclosporine biosynthesis and a model of catalytic promiscuity. Arch Biochem Biophys. 2013;529:55-65.

8. Im H, Sharpe ML, Strych U, Davlieva M, Krause KL. The crystal structure of alanine racemase from Streptococcus pneumoniae, a target for structurebased drug design. BMC Microbiol. 2011;11:116.

9. Bugg TD, Braddick D, Dowson CG, Roper DI. Bacterial cell wall assembly: still an attractive antibacterial target. Trends Biotechnol. 2011;29:167-73.

10. Anthony KG, Strych U, Yeung KR, Shoen CS, Perez O, Krause KL, Cynamon $\mathrm{MH}$, Aristoff PA, Koski RA. New classes of alanine racemase inhibitors identified by high-throughput screening show antimicrobial activity against Mycobacterium tuberculosis. PLoS One. 2011;6:e20374. 
11. Azam MA, Jayaram U. Inhibitors of alanine racemase enzyme: a review. J Enzyme Inhib Med Chem. 2016;31:517-26.

12. Sharma V, Gupta P, Dixit A. In silico identification of putative drug targets from different metabolic pathways of Aeromonas hydrophila. In Silico Biol. 2008;8:331-8.

13. Thompson RJ, Bouwer HG, Portnoy DA, Frankel FR. Pathogenicity and immunogenicity of a Listeria monocytogenes strain that requires $d$-alanine for growth. Infect Immun. 1998;66:3552-61.

14. Chacon O, Bermudez LE, Zinniel DK, Chahal HK, Fenton RJ, Feng Z, Hanford K, Adams LG, Barletta RG. Impairment of D-alanine biosynthesis in Mycobacterium smegmatis determines decreased intracellular survival in human macrophages. Microbiology. 2009;155:1440-50.

15. Awasthy D, Bharath S, Subbulakshmi V, Sharma U. Alanine racemase mutants of Mycobacterium tuberculosis require D-alanine for growth and are defective for survival in macrophages and mice. Microbiology. 2012;158: 319-27.

16. Zajdowicz SL, Jones-Carson J, Vazquez-Torres A, Jobling MG, Gill RE, Holmes RK. Alanine racemase mutants of Burkholderia pseudomallei and Burkholderia mallei and use of alanine racemase as a non-antibiotic-based selectable marker. PLoS One. 2011;6:e21523.

17. Espaillat A, Carrasco-López C, Bernardo-García N, Pietrosemoli N, Otero LH, Álvarez L, de Pedro MA, Pazos F, Davis BM, Waldor MK, Hermoso JA, Cava F. Structural basis for the broad specificity of a new family of amino acid racemases. Acta Crystallogr D Biol Crystallogr. 2014;70:79-90.

18. Kyshe-Andersen J. Electroblotting of multiple gels: a simple apparatus without buffer tank for rapid transfer of proteins from polyacrylamide to nitrocellulose. J Biochem Biophys Methods. 1984;10:203-9.

19. Liu D, Liu XP, Zhang L, Jiao HW, Ju JS, Zhao BH. Biochemical characteristics of an alanine racemase from Aeromonas hydrophila HBNUAh01. Mikrobiologiya. 2015;84:202-9.

20. Liu D, Zhang L, Xue W, Wang YP, Ju JS, Zhao BH. Knockout of the alanine racemase gene in Aeromonas hydrophila HBNUAh01 results in cell wall damage and enhanced membrane permeability. FEMS Microbiol Lett. 2015; 362:fnv089. https://doi.org/10.1093/femsle/fnv089.

21. Wang YP, Yang C, Xue W, Zhang T, Liu XP, Ju JS, Zhao BH, Liu D. Selection and characterization of alanine racemase inhibitors against Aeromonas hydrophila. BMC Microbiol. 2017;17:122.

22. Li N, Sun YM, Tian LY, Zhao BH. The isolation and identification of Aeromonas hydrophila. J Hebei Normal Univ /Nat Sci Ed. 2009;33:240-3.

23. Thompson KD, Ardó L, Verjan N, Han HJ, Jeney G, Hirono I, Aoki T, Adams A. Production and efficacy of an Aeromonas hydrophila recombinant S-layer protein vaccine for fish. Vaccine. 2010;28:3540-7.

24. Choudhury S, Pattnaik P, Sree A, Bapuji M, Mukherjee SC. Antibacterial activity of sponge extracts against fish pathogens. Aquac Res. 2003;34:1075-7.

25. Joerink M, Ribeiro CM, Stet RJ, Hermsen T, Savelkoul HF, Wiegertjes GF. Head kidney-derived macrophages of common carp (Cyprinus carpio L.) show plasticity and functional polarization upon differential stimulation. J Immunol. 2006;177:61-9.

26. Wallis RS, Palaci M, Vinhas S, Hise AG, Ribeiro FC, Landen K, Cheon SH, Song HY, Phillips M, Dietze R, Ellner JJ. A whole blood bactericidal assay for tuberculosis. J Infect Dis. 2011;183:1300-3.

27. Ji Y, Li J, Qin Z, Li A, Gu Z, Liu X, Lin L, Zhou Y. Contribution of nuclease to the pathogenesis of Aeromonas hydrophila. Virulence. 2015;6:515-22.

28. Pianetti A, Falcioni T, Bruscolini F, Sabatini L, Sisti E, Papa S. Determination of the viability of Aeromonas hydrophila in different types of water by flow cytometry, and comparison with classical methods. Appl Environ Microbiol. 2005:71:7948-54.

29. Rey A, Verján N, Ferguson HW, Iregui C. Pathogenesis of Aeromonas hydrophila strain KJ99 infection and its extracellular products in two species of fish. Vet Rec. 2009;164:493-9.

30. Jiang Q, Chen W, Qin Y, Huang L, Xu X, Zhao L, Yan Q. AcuC, a histone deacetylase, contributes to the pathogenicity of Aeromonas hydrophila. Microbiologyopen. 2017. https://doi.org/10.1002/mbo3.468.

31. Kong W, Huang L, Su Y, Qin Y, Ma Y, Xu X, Lin M, Zheng J, Yan Q. Investigation of possible molecular mechanisms underlying the regulation of adhesion in Vibrio alginolyticus with comparative transcriptome analysis. Antonie Van Leeuwenhoek. 2015;107:1197-206.

32. Rasmussen-Ivey CR, Figueras MJ, Donald MG, Liles MR. Virulence factors of Aeromonas Hydrophila: in the wake of reclassification. Front Microbiol. 2016; 7:1337.
33. Sirisena DM, MacLachlan PR, Liu SL, Hessel A, Sanderson KE. Molecular analysis of the $r f a D$ gene, for heptose synthesis, and the rfaF gene, for heptose transfer, in lipopolysaccharide synthesis in Salmonella typhimurium. J Bacteriol. 1994;176:2379-85.

34. Lin J, Huang S, Zhang Q. Outer membrane proteins: key players for bacterial adaptation in host niches. Microb Infect. 2002;4:325-31.

35. Nikaido H. Molecular basis of bacterial outer membrane permeability revisited. Microbiol Mol Biol Rev. 2003;67:593-656.

36. Altarriba M, Merino S, Gavín R, Canals R, Rabaan A, Shaw JG, Tomás JM. A polar flagella operon ( $f(g)$ of Aeromonas hydrophila contains genes required for lateral flagella expression. Microb Pathog. 2003:34:249-59.

37. Suarez G, Sierra JC, Sha J, Wang S, Erova TE, Fadl AA, Foltz SM, Horneman AJ, Chopra AK. Molecular characterization of a functional type $\mathrm{VI}$ secretion system from a clinical isolate of Aeromonas hydrophila. Microb Pathog. 2008; 44:344-61.

38. Vilches S, Urgell C, Merino S, Chacón MR, Soler L, Castro-Escarpulli G, Fiqueras MJ, Tomás JM. Complete type III secretion system of a mesophilic Aeromonas hydrophila strain. Appl Environ Microbiol. 2004;70:6914-9.

39. Zhang WW, Sun K, Cheng S, Sun L. Characterization of DegQVh, a serine protease and a protective immunogen from a pathogenic Vibrio harveyi strain. Appl Environ Microbiol. 2008;74:6254-62.

40. Chopra AK, Houston CW. Enterotoxins in Aeromonas-associated gastroenteritis. Microbes Infect. 1999;1:1129-37.

\section{Ready to submit your research? Choose BMC and benefit from:}

- fast, convenient online submission

- thorough peer review by experienced researchers in your field

- rapid publication on acceptance

- support for research data, including large and complex data types

- gold Open Access which fosters wider collaboration and increased citations

- maximum visibility for your research: over $100 \mathrm{M}$ website views per year

At $\mathrm{BMC}$, research is always in progress.

Learn more biomedcentral.com/submissions 